\title{
Perspectivas de la endocrinología para el año 2003
}

\author{
William Rojass (;. MD).
}

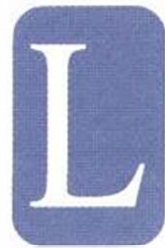

a endocrinología es el área de la medicina que más ha progresado en los últimos años. Estos adelantos no sólo han sido clínicos sino también en ayudas diagnósticas y en biología molecular e inmunología.

En el área clínica se hal avanzado por el desarrollo de nuevos fármacos y hormonas sintéticas similares a las humanas, que hacen los tratamientos más fisiológicos y tolerables para el organismo; el laboratorio hat desarrollado grandes avances, desde el desarrollo inicial de los métodos de radioinmunoanálisis hasta los procesos actuales de fotoquimioluminiscencia. Pero no sólo la posibilidad de medición ha avanzado sino también se ha acelerado la rapidez de los procesos, de tal modo que en la actualidad la determinación de cualquiera de las hormonas que se analizan en forma rutinaria en la práctica clínica no dura más de 4.5 minutos. cuando antes podía tardar días. Por último, los mayores avances se han presentado en el campo de la biología molecular pues, mediante ésta. el conocimiento de la fisiología del ser humano se ha complementado de una manera ni siquiera imaginada hace un siglo.

De acuerdo con lo anterior, podría decirse yue las perspectivas para la endocrinología, no sólo en el 2003 sino en los siguientes 10 años, podrían ser muy halagiieñas.

Sin embargo, este futuro tan prometedor para el desarrollo del conocimiento presenta nubes que ensombrecen el panorama del ejercicio de la especialidad, al menos en nuestro país, que no es muy diferente al de otros sitios. Desde el punto de vista científico, la endocrinología es una especialidad que se relaciona con la mayoría de las otras especialidades médicas, a tal punto que afecciones de naturaleza hormonal como el síndrome de ovario poliquístico lo manejan los ginecólogos; el feocromocitoma los nefrólogos: las dislipidemias, ejemplo típico de enfermedad metabólicar. los cardiólogos; la osteoporosis, enfermedad endocrina del hueso, los reumatólogos, los ginecólogos, los ortopedistas; y así sucesivamente.

Esto puede ocurrir por afinidad de los sistemas que estudian, pero, lamentablemente. éstos también pueden ser movidos por las tendencias comerciales de los laboratorios farmacéuticos, que promocionan sus productos en los nichos científicos donde más se pueden formular. En este sentido, es mejor promover una estatina de última generación ante 150)() cardiólogos que manejan enfermedad coronaria, que 15() endocrinólogos que tratan la dislipidemia. Otro aspecto del ejercicio de la especialidad, que ha creado un obstáculo para el desarrollo de la misma en nuestro medio, es la remuneración de los profesionales. Dentro de las especialidades médicas. las áreas con mejores ingresos son aquellas que tienen procedimientos quirúrgicos o diagnósticos, como la gastroenterología, la cardiología o la hematología. En la nuestra, el único procedimiento que hacemos es la biopsia aspirativa con aguja fina de tiroides, que también la hacen radiólogos. patólogos, cirujanos de cuello o arriesgados internistas. Por lo tanto, nuestros ingresos están soportados sólo por la consulta. y no quiero mencionar aquí cuánto paga una empresa promotora de salud (EPS), así, no es alta la rentabilidad. En términos económicos, esto se podría compensar con el volumen de consulta. pero viene otro obstáculo: las dislipidemias las manejan los cardiólogos, la osteoporosis los reumatólogos y la diabetes, salvo excepciones que confirman la norma, algunos médicos generales que hacen uno año de entrenamiento en diabetes en Argentina y llegan con el título de diabetólogos. Quiero imaginarme qué sucedería si a los neumólogos les llegaran los médicos generales asmólogos: o a los hematólogos los anemiólogos, y a los cardiólogos los coronariólogos.

Pero no todo puede ser negativo. Así como hemos perdido en parte el manejo de algunas enfermedades endocrinas, hemos ganado en otras que por lo regular eran quirúrgicals. Así, estamos enfrentando la acromegalia con tratamiento médico; los prolactinomas ya no son de solución cuirúrgica salvo algunas indicaciones especiales: ya se piensa en la hipertensión arterial de naturaleza endocrina y cada vez más estamos manejando alteraciones ginecológicas de origen endocrino. El desarrollo cientílico de la especialidad la está convirtiendo en invitada obligada a todos los congresos, pues sus enfermedades están en relación intima con el dominio de la biología molecular. circunstancia similar a lo que sucedió con la epidemiología clínica, que pasó de herramienta estadística a ser la protagonista estrella de todos los congresos, por aquello de la medicina basada en la evidencia.

En nuestro medio hay hastante por hacer en este sentido y la Sociedad Colombiana de Endocrinología está trabajando en la certificación de los especialistas; se están creando grupos de trabajo multidisciplinario para el manejo de patologías como cáncer de tiroides, tumores hipolisiarios, clínical de osteoporosis, etc, y en nuestro hospital de San José, la Clínica de Tiroides es reconocida localmente. Se está reiniciando la Clínica de Patología Selar, está el proyecto de hacer la Clínical de Osteoporosis. la de (Obesidad, y orgullosamente somos desde hace cinco años, la especialidad médica con el más alto índice de consulta.

Jefe Servicio de Endocrinologia Hospital de San Josè. 